\title{
Bowel Fistulas
}

\author{
Chernopolsky P*, V Bozhkov, V Draganova, D Chaushev, I Plachkov and R Madjov \\ UMHAT", St. Marina"- MU- Varna, Hr. Smirnenski" 1 str, Varna, Bulgaria
}

*Corresponding author: Plamen Chernopolsky, Second department of Surgery, UMHAT", St. Marina"- MU- Varna, Hr.

Smirnenski" 1 str, Varna, Bulgaria

\section{ARTICLE INFO}

Received: 慧 January 19, 2021

Published: 幽 January 26, 2021

Citation: Chernopolsky P, V Bozhkov, V Draganova, D Chaushev, I Plachkov, R Madjov. Bowel Fistulas. Biomed J Sci \& Tech Res 33(3)-2021. BJSTR. MS.ID.005398.

Keywords: Bowel Fistula; Bowel Obstruction; Surgical Treatment

\section{ABSTRACT}

Background: A fistula is an abnormal communication between two epithelialized surfaces. Bowel fistula presents communication between the bowel lumen and the skin of the abdomen wall, two portions of the intestine or between the intestines and some other hollow organs.

Patients and Results: 21 patients with bowel-cutaneous fistulas between January 2010 and December 2016 were admitted in the Department. The reasons for hospitalization of patients were following symptoms: bowel obstruction, abdominal pain, intestinal content draining from the abdominal incision, abdominal wall infection. Diagnosis was established on the clinical presentation, performance status and imaging procedures (ultrasonography, CT, and MRI). All of them had previous GI surgery. Surgical treatment was performed in all patients and included bowel resection, followed by sideto-side or end-to-end anastomosis, stoma construction and in some cases abdominal wall reconstruction with prosthesis.

Conclusion: Despite significant advances in the management in last decades, bowel fistulas still remain a major clinical problem with serious mortality rate of $15-25 \%$. Operative treatment is necessary in 35 to $80 \%$ of patients in order to achieve closure.

\section{Introduction}

A fistula is an abnormal communication between two epithelialized surfaces [1-3]. Bowel fistula presents communication between the bowel lumen and the skin of the abdomen wall, two portions of the intestine or between the intestines and some other hollow organs.

\section{Materials and Methods}

16 patients with bowel-cutaneous fistulas between January 2013 and December 2016 were admitted in the Department. Ratio males: females $-1,66: 1$ ( 6 females and 10 males). The median age of the patients was 64,9 . According to age most of the fistulas were found at the age of 60-80 years $-68,7 \%$ (Table 1 ).

Table 1: Age of the patients with bowel fistula.

\begin{tabular}{|c|c|}
\hline $\begin{array}{c}\text { Age of the Patients with Bowel Fistulas ( } \\
\text { years) }\end{array}$ & Number of Patients \\
\hline $40-50$ & $1(6,25 \%)$ \\
\hline $50-60$ & $3(18,8 \%)$ \\
\hline $60-70$ & $5(31,2 \%)$ \\
\hline $70-80$ & $6(37,5 \%)$ \\
\hline $80-90$ & $1(6,25 \%)$ \\
\hline
\end{tabular}

According to localization we divide fistulas in two main groups:

1. Small bowel fistulas $-7(43,8 \%)$

2. Large bowel fistulas $-9(56,2 \%)$

According to output we divide fistulas in two main groups:

1. High output fistulas - greater than $500 \mathrm{ml}$ per day usually originating from the small bowel - $10(62,5 \%)$

2. Low output fistulas - less than $200 \mathrm{ml}$ per day - $6(37,5 \%)$

Most of the patients had previous GI surgery or any other surgical procedures (gynecological or urological), except 3 patients - both with complication of Crohn disease and one with prostate cancer after placing a urethral catheter, which pass through rectal lumen [4-6]. Cancer was a reason for operation and fistula in 5 cases -4 patients with colorectal and the 1 with prostate cancer.

\section{Clinical Presentation}

The reasons for hospitalization of patients were following symptoms: bowel obstruction, abdominal pain, intestinal content draining from the abdominal incision, abdominal wall infection, and 
fever. Of course, there were symptoms of the main disease, which was the reason for the fistula - cancer, Crohn disease, postoperative hernia. Diagnosis was established on the clinical presentation, performance status and imaging procedures (ultrasonography, CT and MRI) - (Figure 1). Surgical treatment included bowel resection, followed by side-to-side or end-to-end anastomosis, stoma construction in 12 patients (75\%) and in some cases abdominal wall reconstruction with prosthesis (Figures 2-4).
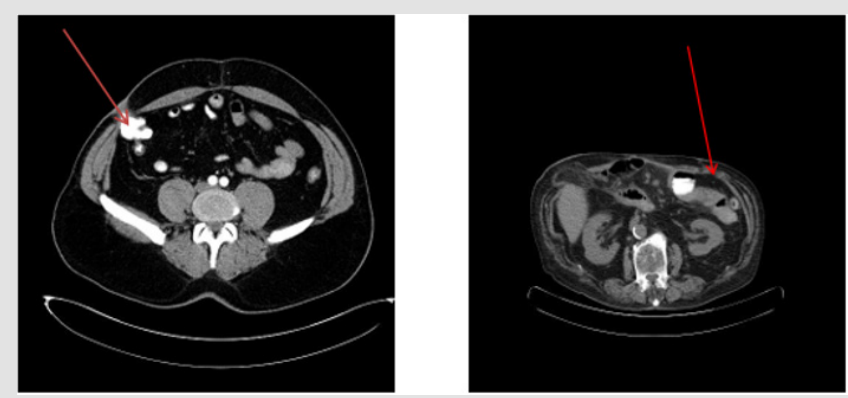

Figure 1: Two cases with colocutaneous fistula.

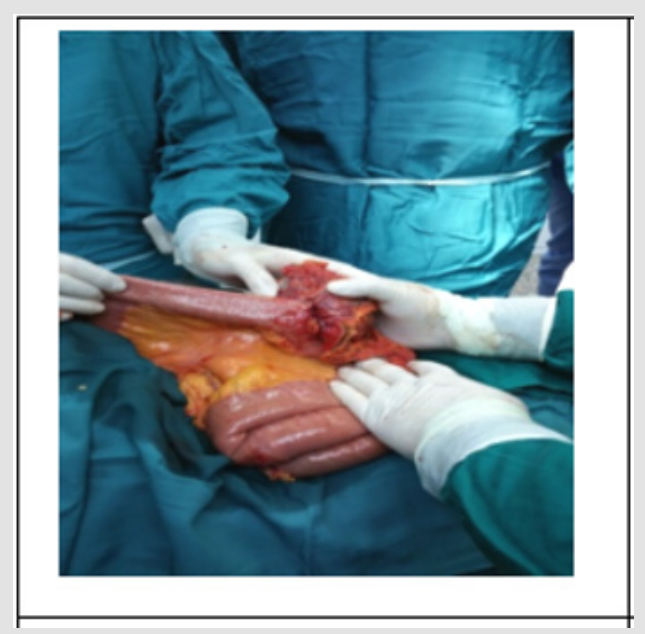

Figure 2: Bowel cancer with fistula.

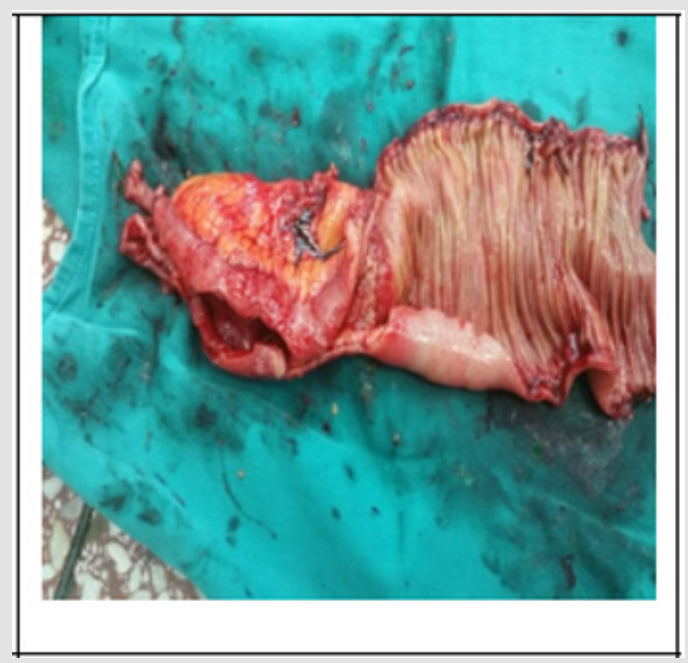

Figure 3: Crohn disease with fistula.

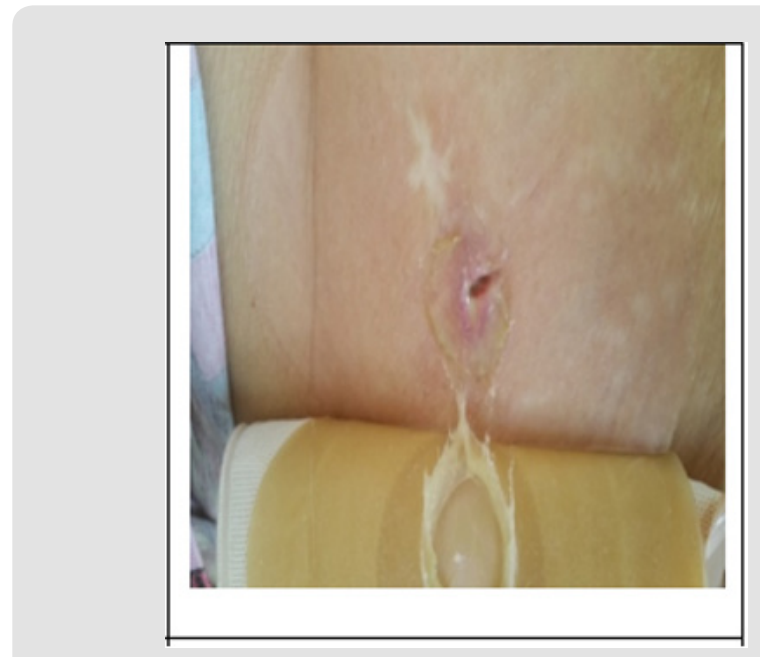

Figure 4: Colocutaneous fistula.

\section{Discussion}

The spectrum of bowel fistulas ranges from an easily managed, low-output colocutaneous fistula to a high-output enterocutaneous fistula in the midst of an open abdomen requiring many months of intensive care, nutritional support, and complex reconstructive surgery. We mainstay on four cardinal principles in the initial care of patients with bowel fistulas:

- Adequate nutrition,

- Drainage of abscesses and avoidance of sepsis,

- Control and maintenance of the fistula drainage site,

- $\quad$ Protection of the skin - appropriate treatment of infection

\section{Strategy}

Non-operative management - Although dependent on the etiology of the fistula - if no distal obstruction is present, if no foreign body is involved, if the tract is long, if there is a low output, and if there is no active infection [7]. Numerous studies have delineated the important determinants associated with decreasing the time to closure of a fistula and decreasing a patient's overall associated morbidity and mortality. We apply conservative management of enteric fistulas for periods of up to 3 months.

Factors to consider for fistulas that do not spontaneously close include the following:

- $\quad$ Malignancy

- $\quad$ Foreign bodies in the fistula tract

- $\quad$ Short fistula tracts with epithelialization

- $\quad$ Undrained abscess cavities

- Distal obstruction

- $\quad$ Radiation enteritis

- $\quad$ Active IBD of the involved bowel segment

- High-output status for the fistula 
Indications for surgery for intestinal fistulas we classified into those related to early surgical intervention and those related to delayed intervention [8]. Deciding between early and delayed surgical intervention is complicated and depends on multiple prognostic factors.

We apply early surgery in the following circumstances:

- Sepsis or abscess formation not amenable to percutaneous drainage

- $\quad$ Complete distal intestinal obstruction

- Uncontrolled bleeding from fistula

- Removal of mesh or other foreign bodies

- Inability to control the fistula without surgical drainage.

Delayed surgery is most commonly indicated in patients whose fistulas have not healed after several (typically 4-8) weeks of comprehensive conservative treatment. Specific indications include the following:

- $\quad$ Continued high output from fistula after patient has been given nothing by mouth and started on parenteral nutrition.

- Continued signs of infection after institution of adequate antibiotic therapy and drainage of associated abscesses

- Uncontrolled bleeding

Bearing in mind the referenced studies cited in the literature and our own experience, the principles that should govern the management of small intestine external fistulae can be summarized as follows:

- $\quad$ Small bowel fistulae initially require aggressive treatment and in most cases may be managed conservatively.

- Mortality rates and recovery can be improved by early accurate diagnosis and treatment of septic patients.

- Adequate output control has a significant impact on clinical and nutritional recovery.

ISSN: 2574-1241

DOI: 10.26717/BJSTR.2021.33.005398

Chernopolsky P. Biomed J Sci \& Tech Res (C) (i) This work is licensed under Creative

Submission Link: https://biomedres.us/submit-manuscript.php
- $\quad$ Once the patient is stabilized, efforts must be made to optimize nutritional recovery.

- $\quad$ Complicated and persistent fistulae require reconstructive surgery yet should only be attempted when feasible. The timing of surgical intervention should be adapted to each particular case depending on the clinical and nutritional state along with the pathological and surgical history of the patient.

\section{Conclusion}

In recent years, a progress has been made in the management of this complication. Improved diagnostic methods, better control and treatment of sepsis, nutritional support and new resources for local wound care have, to some extent, reduced concomitant mortality. Despite significant advances in the management in last decades, bowel fistulas still remain a major clinical problem with serious mortality rate of $15-25 \%$. Operative treatment is necessary in 35 to $80 \%$ of patients in order to achieve closure.

\section{References}

1. Berry SM, Fischer JE (1996) Classification and pathophysiology of enterocutaneous fistulas. Surg Clin North Am 76(5): 1009-1018.

2. Chintapatla S, Scott NA (2002) Intestinal failure in complex gastrointestinal fistulae. Nutrition 18(11-12): 991-996.

3. Daniel E Wainstein, Victoria Tüngler, Constanza Ravazzola, Osvaldo Chara (2011) Management of external small bowel fistulae: Challenges and controversies confronting the general surgeon. International Journal of Surgery 9(3): 198-203.

4. Demetriades D (2003) A technique of surgical closure of complex intestinal fistulae in the open abdomen. J Trauma 55(5): 999-1001.

5. Diego I Cattoni, Constanza Ravazzola, Victoria Tüngler, Daniel E Wainstein, Osvaldo Chara (2011) Effect of intestinal pressure on fistula closure during vacuum assisted treatment: A computational approach. International Journal of Surgery 9 (8): 662-668.

6. Lynch AC, Delaney CP, Senagore AJ, Connor JT, Remzi FH, et al. (2004) Clinical outcome and factors predictive of recurrence after enterocutaneous fistula surgery. Ann Surg 240(5): 825-831

7. Osborn C, Fischer E (2009) How I do it: gastrointestinal cutaneous fistulas. J Gastrointest Surg 13(11): 2068-2073.

8. Schein M (2008) What's new in postoperative enterocutaneous fistulas? World J Surg 32(3): 336-338.

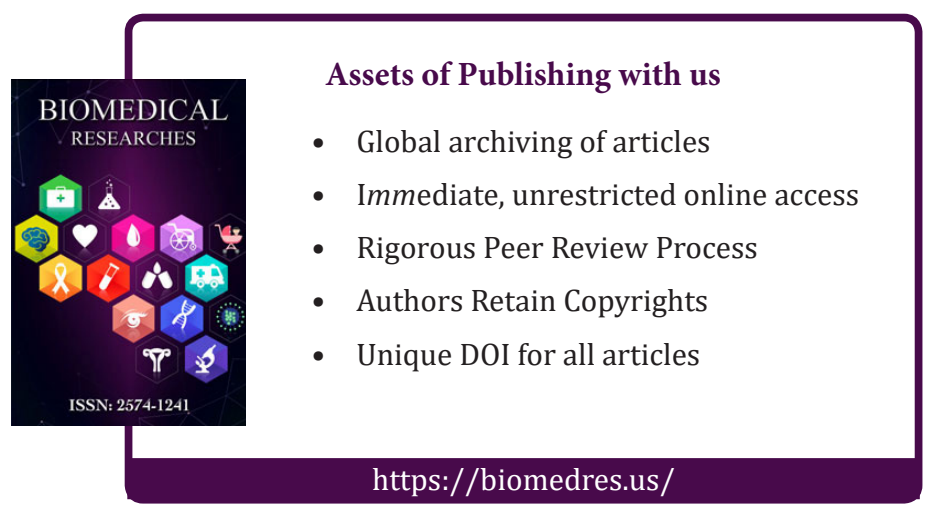

